\title{
REVIEW
}

\section{The palmomental reflex: a useful clinical sign?}

\section{G Owen, G P Mulley}

The palmomental reflex, an involuntary contraction of the mentalis muscle of the chin caused by stimulation of the thenar eminence, can be tested easily and rapidly. Its presence may alert the clinician to the possibility of cerebral pathology. However, the reflex is often present in normal people and may be absent in disease states. Testing merely for the presence or absence of the reflex therefore lacks both specificity and sensitivity. A strong, sustained, and easily repeatable contraction of the mentalis muscle, which can be elicited by stimulation of areas other than the palm, is more likely to indicate cerebral damage.

See end of article for authors' affiliations

\section{Correspondence to:} Professor G P Mulley; graham.mulley@leedsth. nhs.uk

Received

15 November 2000 Accepted 16 May 2001
S timulation of the thenar eminence can cause an involuntary contraction of the mentalis muscle of the chin. This reflex is known as the palmomental or palm-chin reflex.

This reflex was first described by Marinesco and Radovici in 1920. ${ }^{1}$ In a young patient with amyotrophic lateral sclerosis they observed a slow, sustained contraction of the ipsilateral chin muscles in response to stoking the palm with a pin or light touch to the thenar eminence. The reflex could also be elicited by stimulating other areas of the skin or by urethral catheterisation, though the response was less pronounced. The reflex was first believed to signify damage to the pyramidal tract but it was later shown in many normal people. ${ }^{1}$ However, in healthy people the trigger or release area was found to be confined to the palm and the response was weaker, short lived, and easily fatiguable.

The palmomental reflex is described in textbooks of neurology and books on clinical examination, ${ }^{2}$ but some authors have questioned its diagnostic value. ${ }^{4}$ Here we review the evidence on the epidemiology, pathophysiology, and clinical importance of the palmomental reflex. We have collected these data from English language papers identified in Medline, from searching the bibliographies of all papers found, and from the seminal publications of Marinesco and Radovici.
J Neurol Neurosurg Psychiatry 2002;73:113-115

\section{EPIDEMIOLOGY}

The reflex may be present in healthy people of all ages. The prevalence of the palmomental reflex is unknown because of the variability in the means of eliciting the reflex and the interpretation of its presence (table 1). ${ }^{5-8}$

In an early study of workhouse residents in Bucharest there was no increase in the prevalence of the reflex with advancing age. ${ }^{9}$ The prevalence rates for the 50 to 60 age group and the 80 to 90 age group were $66 \%$ and $61 \%$, respectively. However, the study included only 18 people between the ages of 80 and 90 years and 3 people over the age of 90 . Subsequent studies suggested that the prevalence of the reflex falls during childhood and then increases during adult life. ${ }^{51011}$ It occurs in between $2.5 \%$ and $50 \%$ of healthy adults between 20 and 60 years of age. ${ }^{16710-14}$ A large Japanese study reported respective prevalence rates of $2.5 \%$ and $53.5 \%$ in students and older hospital patients. ${ }^{8}$

\section{HOW TO ELICIT A PALMOMENTAL REFLEX}

Since the original description, several methods of eliciting the reflex have been proposed. ${ }^{1}$ Most authors suggest stroking the thenar eminence in a proximal to distal direction using a sharp object such as the pointed end of a reflex hammer, key, paper clip, or fingernail. ${ }^{6711}$ The stimulus should cause discomfort but not pain. Contraction of the ipsilateral, contralateral, or both mentalis muscles may then be observed. ${ }^{78}$

Others have elicited the reflex by stimulation of the hypothenar eminence, palmar aspect of the thumb, forearm, chest, abdomen, or even the sole. ${ }^{1}{ }^{1315} 16$ The presence of such a large receptive field has led to the proposal of the term "mentalis reflex" ${ }^{17}$ More recent studies confirm that the reflex's trigger area is usually confined to the palms of healthy people but can extend to a much greater area in neurological patients. ${ }^{13} 16$

\section{CLINICAL CHARACTERISTICS}

There are different definitions of a positive response (table 1). Some have classified it as the electromyographic detection of muscle activity. ${ }^{18}$ Others have defined the persisting contraction of

Table 1 Examples of the methods used to elicit the palmomental reflex

\begin{tabular}{|c|c|c|}
\hline Author and reference & Method & Definition of a positive response \\
\hline Little and Masotti ${ }^{5}$ & Firmly scratching thenar eminence with an applicator stick & Contraction of mentalis muscle on two or more occasions \\
\hline Jacobs and Gossman ${ }^{6}$ & Briskly stroking along the thenar eminence with a key & Contraction of ipsilateral mentalis muscle \\
\hline Marti-Vilalta and Graus ${ }^{7}$ & $\begin{array}{l}\text { Stroking the thenar eminence with the nail of the index finger by } \\
\text { two examiners on different occasions }\end{array}$ & Weak or strong contraction of the mentalis muscle \\
\hline Otomo $^{8}$ & Stroking the thenar eminence with a key & Five successive contractions of the mentalis muscle \\
\hline
\end{tabular}


the mentalis muscle on the fifth consecutive stimulation as a positive response. ${ }^{8}$ Many accept a visible contraction of the mentalis muscle as a positive reaction. ${ }^{6} 713$

The reflex is easily exhaustible in healthy people but is less fatiguable when neurological disease is present. ${ }^{17}{ }^{13}$ Clinical gradings of the reflex based on the strength of contraction of the mentalis muscle have been proposed. ${ }^{10}$ Studies have confirmed the original observations of Marinesco and Radovici; there are weaker responses in healthy people and stronger responses in neurological patients. ${ }^{7}$ The reflex may disappear during recovery from subarachnoid haemorrhage and subdural haematoma. ${ }^{19}$ The presence and strength of the response also vary according to the person's level of anxiety or arousal. In a study of army recruits there was rise in the incidence of the reflex immediately before rifle practice. ${ }^{20}$

The reflex is not of value in identifying the site of cerebral pathology. ${ }^{19}$ In nine patients with a unilateral palmomental reflex, five had bilateral lesions, two had contralateral lesions, and two had an ipsilateral injury.

\section{NEUROPHYSIOLOGICAL CHARACTERISTICS}

The use of needle electrodes to record action potentials within skeletal muscle (electromyography) has shown the universal presence of the palmomental reflex in patients and medical student volunteers. ${ }^{17}$ A stimulus of sufficient strength produces a contraction of the mentalis muscle in all subjects.

Caccia $e a^{18}$ provide detailed electromyographic data on the palmomental reflex in volunteers between the ages of 23 and 48. They observed the reflex electromyographically but not clinically in 16 of $23(70 \%)$ healthy people. An ipsilateral response was recorded in 13, a bilateral response in two, and a contralateral response in one. In most cases the first stimulus would elicit an early (R1) and a late (R2) response. The mean latencies of the first and second responses were $30 \mathrm{~ms}$ and $112 \mathrm{~ms}$, respectively. Stimuli delivered at a rate of $0.5 \mathrm{~Hz}$ led to a fusion of the responses by the fourth stimulus. The response disappeared by the 10th stimulus in all cases.

Two different neural pathways may account for the wide range of latencies. ${ }^{18}$ The common afferent pathway consists of the cutaneous and muscular receptors of the thenar eminence and the median nerve. The common efferent pathway involves the motor nuclei of the facial nerve. Longer latencies may involve the thalamus and motor cortex and shorter latencies may result from brainstem integration of the reflex..$^{18}$

A further study examined the neurophysiological characteristics of the palmomental reflex in untreated and treated parkinsonian patients and controls of a similar age. ${ }^{21}$ On stimulation of the thenar and hypothenar areas, no difference was found between the prevalence of the reflex in patients and that in controls. Habituation and contralateral response rates were similar in patients with Parkinson's disease and in controls. A shorter reflex latency and duration were seen in the parkinsonian patients. Stimulation of the hypothenar eminence in the younger controls of the previous electromyographic study did not elicit the reflex. ${ }^{18}$ Bilateral or contralateral responses were more frequently observed in parkinsonian patients than in younger people. ${ }^{18} 21$

These observations have led to suggestions that cortical inhibition of reflex and decussating brainstem pathways is lost with aging and disease states. ${ }^{18} 21$

\section{SPECIFIC MEDICAL CONDITIONS}

The reflex is commoner in patients with such neurological diseases as stroke, multiple sclerosis, motor neurone disease, and cerebral tumours. ${ }^{781319}$ It is also commoner in those who have suffered severe head injuries. ${ }^{19}$

A high prevalence has been reported in Down's syndrome, ${ }^{522}$ AIDS, ${ }^{23}$ and vibroacoustic disease. ${ }^{24}$ (Vibroacoustic disease is a systemic disorder caused by exposure to large pressure amplitude, low frequency noise. The disease is characterised by a proliferation of the extracellular matrix of connective tissue. It may lead to cognitive problems, balance disorders, and epilepsy.) The conclusions of the first two studies must be treated cautiously, as there were no healthy controls. The presence of the reflex does not correlate with functional ability in cases of Down's syndrome, but the reflex is increasingly prevalent with advancing stages of HIV disease. ${ }^{23}$

Some report a higher prevalence in Parkinson's disease with the reflex becoming commoner and stronger with the degree of akinesia. ${ }^{25}$ Others have found a similar prevalence in Parkinson's disease and healthy people. ${ }^{27}$ Huber and Paulson ${ }^{28}$ were unable to find a change in reflex prevalence related to levodopa administration but confirmed that the reflex was commoner in advanced disease.

\section{THE PALMOMENTAL REFLEX IN PSYCHIATRY}

The palmomental reflex is commoner in patients with organic and functional psychoses than in age matched controls. ${ }^{29}$ In a survey of schizophrenic patients with and without tardive dyskinesia, there were no significant differences in the prevalence of the palmomental reflex. ${ }^{30}$ However, the snout, corneomandibular, and glabellar reflexes were commoner in patients with involuntary movements.

Several authors have examined the prevalence of the palmomental reflex in patients with dementia. Paulson and Gottlieb's study of 85 "senile" patients, with a mean age of 62 years, reported a prevalence rate $21 \%{ }^{31}$ In Alzheimer's disease reported prevalence rates range from $2.5 \%{ }^{32}$ to $54 \% .^{33}$ In the study reporting the lower prevalence rate, $41 \%$ of the participants were living at home, whereas in the second study all participants lived in a care home. However, two other studies have failed to find an association between the presence and intensity of the reflex with cognitive and functional impairment. ${ }^{34} 35$ In a study of 20 patients with vascular dementia the reflex was present in over $70 \%{ }^{36}$

In a large Canadian study the primitive reflexes of 2900 older people were examined. ${ }^{37}$ The palmomental reflex was present in $7.8 \%$ of cognitively intact people, $15.8 \%$ of the cognitively impaired people, and $25.8 \%$ of those with dementia. The authors concluded that the palmomental reflex is not sensitive enough to act as a marker of dementia.

\section{THE PALMOMENTAL REFLEX IN CHILDREN}

The reflex can be elicited in most small premature infants regardless of whether they are awake, asleep, or comatose.$^{38}$ In an electromyographic study of 18 full term infants between one and six days old, the reflex was present bilaterally in 17 of the infants and unilaterally in one. ${ }^{39}$ A clinical study of infants between the second and fifth day of life found that the reflex

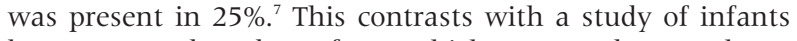
between 1 and 21 days of age, which suggested a prevalence rate of $6.6 \%$, increasing to $13 \%$ after feeding. ${ }^{11}$ Another clinical study reported a prevalence rate of over $60 \%$ between birth and two years, falling to about $10 \%$ between the ages of 9 and 14. ${ }^{5}$ The reflex has a similar prevalence in healthy adults and adolescents with behavioural disorders. ${ }^{40}$

\section{SUMMARY}

The palmomental reflex can be tested easily and rapidly. Its presence may alert the clinician to the possibility of cerebral pathology. However, the reflex is often present in normal people and may be absent in disease states. Testing merely for the presence or absence of the reflex therefore lacks both specificity and sensitivity. A strong, sustained, and easily repeatable contraction of the mentalis muscle, which can be elicited by stimulation of areas other than the palm, is more likely to indicate cerebral damage. 


\section{Authors' affiliations}

G Owen, G P Mulley, Department of Medicine for the Elderly, St James's University Hospital, Beckett Street, Leeds LS9 7TF, UK

\section{REFERENCES}

1 Marinesco G, Radovici A. Sur un reflexe cutane nouveau: reflexe palmo-mentonnier. Rev Neurol 1920;27:237-40.

2 Bannister R. Brain and Bannister's clinical neurology. Oxford: Oxford University Press, 1992.

3 Swash M. Hutchison's clinical methods. London: WB Saunders, 1995

4 Whittle IR, Miller JD. The palmomental reflex. Surg Neurol 1986;26:520-1

5 Little TM, Masotti RE. The palmo-mental reflex in normal and mentally retarded subjects. Dev Med Child Neurol 1974;16:59-63.

6 Jacobs L, Gossman MD. Three primitive reflexes in normal adults. Neurology 1980;30:184-8.

7 Marti-Vilalta JL, Graus F. The palmomental reflex: clinical study of 300 cases. Eur Neurol 1984;23:12-6.

8 Otomo E. The palmomental reflex in the aged. Geriatrics 1965:20:901-5.

9 Radovici A, Schater M, Cohen E. Le reflexe palmo-mentonnier chez les vieillards. Bull Soc Roum Neurol Psychiatr Psychol Endocrinol 1933;5: 187-9.

10 August B, Miller RB. Clinical value of the palmomental reflex. JAMA 1952;148:120-1.

11 Marx P, Reschop J. The clinical value of the palmomental reflex. Neurosurg Rev 1980;3:173-7.

12 Blake JR, Kunkle EC. The palmomental reflex: a clinical and physiological analysis. Arch Neurol Psychiatr 1951;65:337-45.

13 Dalby MA. The diagnostic value of the palmo-mental reflex. Arch Neurol Scand 1970;46:601-8

14 Brown DL, Smith TL, Knepper LE. Evaluation of five primitive reflexes in 240 young adults. Neurology 1998;51:322.

15 Bracha S. The clinical value of the pollico-mental reflex in neuropathology. J Nerv Ment Dis 1958;127:91-5.

16 Ansink JJ. Physiologic and clinical investigations into 4 brainstem reflexes. Neurology 1962;12:320-8

17 Reis DJ. The palmomental reflex. A fragment of a general nociceptive skin reflex: a physiological study in normal man. Arch Neurol 1961:4:30-42.

18 Caccia MR, Osio M, Mangoni A. The palmomental reflex from mechanical stimulation in normal man: normative data. Electromyogr Clin Neurophysiol 1991;31:151-6.

19 Whittle IR, Miller JD. Clinical usefulness of the palmomental reflex. Med J Aust 1987;146:137-9.

20 McDonald JK, Kelley JK, Brock LD, et al. Variability of the palmomental reflex. J Nerv Ment Dis 1963;136:207-15.

21 Caccia MR, Galimberti V, Valla P, et al. Electrophysiology of the palmomental reflex in normal and parkinsonian subjects. Electromyogr Clin Neurophysiol 1996;36:9-13.
22 Sand T, Mellgren SI, Hestnes A. Primitive reflexes in Down's syndrome. J Ment Defic Res 1983;27:39-44.

23 Howlett WP, Nkya WM, Kvale G, et al. The snout and palmomental reflexes in HIV disease in Tanzania. Acta Neurol Scand 1995;91:470-6.

24 Martinho Pimenta AJF, Castelo Branco MSN, Castelo Branco NAA. The palmo-mental reflex in vibroacoustic disease. Aviat Space Environ Med 1999;70(3 suppl):A100-6.

25 Maertens de Noordhout A, Delwaide PJ. The palmomental reflex in Parkinson's disease: comparisons with normal subjects and clinical relevance. Arch Neurol 1988;45:425-7.

26 Vreeling FW, Verhey FRJ, Houx PJ, et al. Primitive relexes in Parkinson's disease. J Neurol Neurosurg Psychiatry 1993;56:1323-6.

27 Gossman MD, Jacobs L. Three primitive reflexes in parkinsonism patients. Neurology 1980:30:189-92.

28 Huber SJ, Paulson GW. Influence of dopamine and disease severity on primitive reflexes in Parkinson's disease. Eur Neurol 1989;29:141-4.

29 Keshavan MS, Vikram Kumar Y, Channabasavanna SM. A critical evaluation of infantile reflexes in neuropsychiatric diagnosis. Indian J Psychiatry 1979;21:267-70.

30 Youssef HA, Waddington JL. Primitive (developmental) reflexes and diffuse cerebral dysfunction in schizophrenia and bipolar effective disorder: over representation in patients with tardive dyskinesia. Biol Psychiatry 1988;23:791-6.

31 Paulson G, Gottlieb G. Development reflexes: the reappearance of foetal and neonatal relexes in aged patients. Brain 1968;9:137-52.

32 Burns A, Jacoby R, Levy R. Neurological signs in Alzheimer's disease. Age Ageing 1991;20:45-51.

33 Basavaraju NG, Silverstone FA, Libow LS, et al. Primitive reflexes and perceptual sensory tests in the elderly: their usefulness in dementia. $J$ Chronic Dis 1981;34:367-77.

34 Bakchine S, Lacomblez L, Palisson E, et al. Relationship between primitive reflexes, extra-pyramidal signs, reflective apraxia and severity of cognitive impairment in dementia of the Alzheimer type. Acta Neurol Scand 1989;79:38-46.

35 Franssen E, Kluger A, Torossian CL, et al. The neurologic syndrome of severe Alzheimer's disease: relationship to functional decline. Arch Neurol 1993;50:1029-39.

36 Vreeling FW, Houx PJ, Jolles J, et al. Primitive reflexes in Alzheimer's disease and vascular dementia. J Geriatr Psychiatry Neurol 1995;8:111-7.

37 Hogan DB, Elby EM. Primitive relexes and dementia: results from the Canadian study of health and ageing. Age Ageing 1995;24:375-81 38 Parmelee AH. The palmomental reflex in premature infants. Dev Med Child Neurol 1963:5:381-7.

39 Caccia MR, Osio M, Tornaghi R, et al. Electrophysiological observations on the palmomental reflex in normal neonates. Neurophysiol Clin 1990;20:455-62.

40 Kleu G. Palmomental reflexes in adolescents with behaviour disorders. Psychiatr Clin (Basel) 1970;3:375-80. 